\title{
Growth performance, intestinal morphology, and meat quality in relation to alpha-lipoic acid associated with vitamin $C$ and $E$ in broiler chickens under tropical conditions
}

\author{
Jaehong Yoo', Young Joo Yi², Bonjin Koo', Samooel Jung ${ }^{1}$, Joung Ung Yoon ${ }^{3}$, Hyun Bae Kang ${ }^{3}$, \\ Do Hun Lee ${ }^{3}$, Jung Min Heo ${ }^{1}$
}

\author{
${ }^{1}$ Chungnam National University, Department of Animal Science and Biotechnology, Daejeon, Republic of Korea. \\ ${ }^{2}$ Chonbuk National University, Division of Biotechnology, Iksan, Republic of Korea. \\ ${ }^{3}$ Biogenoci Co. Ltd., Seoul, Republic of Korea.
}

\begin{abstract}
This study was conducted to examine the effect of alpha-lipoic acid with vitamin $\mathrm{C}$ and $\mathrm{E}$ on growth performance, intestinal morphology, and meat quality in broiler chickens under tropical conditions. A total of 288 one-day-old male ROSS 308 chicks $(40 \pm 0.1 \mathrm{~g})$ were used in a completely randomized design and allotted to one of six dietary treatments to form sixe replicates per treatment (eight birds per cage). The six dietary treatments were: a corn-soybean meal-based diet (NC; no antimicrobial compounds added) with 8 ppm alpha-lipoic acid (ALA); 150 ppm vitamin C and 75 ppm vitamin E (E-75); E-75 plus ALA (E-75-ALA); 150 ppm vitamin C and 50 ppm vitamin E (E-50) plus ALA (E-50-ALA); and 150 ppm vitamin C and 25 ppm vitamin E (E-25) plus ALA (E-25-ALA). All dietary treatments were continuously provided in liquid form, dissolved in water. Birds were housed in a battery cage $(\mathrm{n}=36)$, and were offered dietary treatments on an libitum basis. The ambient temperature was maintained at $32 \pm 1{ }^{\circ} \mathrm{C}$ for the first three weeks and reduced gradually to $28{ }^{\circ} \mathrm{C}$ by the end of the experiment (day 35) to induce moderate tropical condition. One bird per pen $(n=6)$, and another bird per pen $(n=6)$ were euthanized via cervical dislocation to obtain terminal ileum to measure villus height and crypt depth at day 21 , and to harvest breast meat and drumsticks to evaluate meat quality traits at day 35, respectively. Dietary treatment E-75-ALA improved body weight and average daily gain compared with birds fed other dietary treatments from day 1 to day 35 . Birds fed dietary treatment E-75-ALA and E-50-ALA had higher villus height than those fed the other dietary treatments at day 21. Dietary treatments E-75-ALA and E-50-ALA reduced thiobarbituric acid reactive substance (TBARS) in drumsticks compared with other dietary treatments, but only treatment E-75-ALA decreased TBARS in breast meat at day 35. Liquid form of antioxidant compounds such as E-75-ALA can improve growth performance, histology of terminal ileum, and meat quality traits in broiler chickens under moderate tropical condition for 35 days.
\end{abstract}

Key Words: broilers, heat stress, vitamin E, tropical condition

\section{Introduction}

Heat stress is known to be one of the most detrimental factors in overall poultry production (Lara and Rostagno, 2013). Although many studies have clearly elucidated the thermoneutral zone of broilers $\left(18-22{ }^{\circ} \mathrm{C}\right.$; Charles, 2002), it is not easy to maintain that temperature in a specific area or a period or the combination of both. Recent studies have demonstrated that heat stress has affected broiler productivity by reducing feed intake and efficiency, body weight, meat quality, and survivability (Sohail et al., 2012; $\mathrm{Lu}$ et al., 2007). Also, it has been shown that heat stress had immunosuppressant effects on birds and resulted in

Received August 24, 2015 and accepted December 3, 2015

Corresponding author: jmheo@cnu.ac.kr

http://dx.doi.org/10.1590/S1806-92902016000300005

Copyright (C) 2016 Sociedade Brasileira de Zootecnia. This is an Open Access article distributed under the terms of the Creative Commons Attribution License (http://creativecommons.org/licenses/by/4.0/), which permits unrestricted use, distribution, and reproduction in any medium, provided the original work is properly cited. decreasing weights of lymphoid organs, total circulating antibodies, and phagocytic ability of macrophages (Quinteiro-Filho et al., 2012). Basically, birds attempt to maintain their thermal homeostasis from heat stress. During this process, the level of reactive oxygen species (ROS) is increased, the body enters a stage of oxidative stress, and heat shock proteins are released in response to stress, providing protection from ROS effects (Droge, 2002). Therefore, it can be assumed that antioxidant supplementation to the diet could alleviate impaired productivity of broilers in response to heat stress.

Recently, alpha-lipoic acid (ALA) has been used as a potent antioxidant agent, ranging from therapeutic application to dietary supplementation, widely distributed in foods and readily absorbed from the diet (Packer et al., 1995). Reed (1957) demonstrated the basic functions of ALA, including its antioxidant properties for the first time in leaves. Later, Packer et al. (1995) reported that ALA acted on dehydrogenase complexes as a co-factor. Also, ALA and its reduced form, dihydrolipoic acid (DHLA), had a function 
as antioxidants in free-radical quenching, metal chelation, antioxidant recycling, and gene expressing (Packer et al., 1995). Likewise, ALA had the scavenging ability directly against the hydroxyl radical, the hypochlorous radical, and singlet oxygen, but not against the superoxide radical and the peroxyl radical (Suzuki et al., 1991; Scott et al., 1994; Kagan et al., 1992; Stevens et al., 1974). However, DHLA, known to rapidly convert into ALA, is capable of quenching the oxidants that cannot be scavenged by ALA (Kagan et al., 1992). In addition, ALA has shown antioxidant activity by chelating iron, copper, and other transition metals (Packer et al., 1995). Particularly, DHLA interacted with other antioxidants by regenerating cellular antioxidants, such as vitamin $\mathrm{E}$, vitamin $\mathrm{C}$, and glutathione from their radicals or inactive form (Biewenga et al., 1997). Consequently, it appears that DHLA is involved in indirect antioxidative activity.

Numerous studies have been conducted to evaluate the antioxidative effects of ALA on livestock. Bai et al. (2012) determined that ALA supplementation to the diet of sows during late-gestation and lactation improved the activity of antioxidant enzymes in the serum and improved the performance of sows and their nursing piglets. In broiler chickens, dietary ALA inhibited body fat deposition, decreased muscle glycolysis at early postmortem, and improved the water holding capacity, indicating that ALA supplementation could prevent the occurrence of PSE (pale, soft, exudative) meat (El-Senousey et al., 2013). Lipid peroxidation level, superoxide dismutase, and catalase enzyme activities and glutathione amounts in Japanese quail under heat stress conditions were ameliorated with the addition of ALA to the diet (Halıc1 et al., 2012). However, few results have been reported regarding the synergic antioxidative effects of dietary ALA together with vitamins $\mathrm{C}$ and $\mathrm{E}$ in broilers (Sahin et al., 2003).

The objective of this study was, therefore, to evaluate the effects of antioxidants (ALA, vit. E, and vit. C) on growth performance, ileal morphology, and meat quality in broilers under chronic heat stress conditions. This study was also conducted with the purpose of elucidating the optimum levels of supplemented antioxidants in liquid form to the water supplied to broilers reared at a high ambient temperature.

\section{Material and Methods}

The practices and procedures for this experiment were reviewed and approved by the Chungnam National University Animal Ethics Committee (CNU-00521).

A 5-week experiment was conducted with 288 oneday-old male ROSS 308 broilers $(40.0 \pm 0.1 \mathrm{~g})$. Broilers were individually weighed and randomly assigned to one of six dietary treatments; each treatment had six replicates with eight birds per pen. All birds were raised in stainless steel battery cages of identical size $(86 \mathrm{~cm}$ width $\times 57 \mathrm{~cm}$ length $\times 35 \mathrm{~cm}$ height) and provided with continuous lighting $(24 \mathrm{~h})$. The initial ambient temperature of the room was maintained at $32 \pm 1{ }^{\circ} \mathrm{C}$ for the first three weeks and decreased gradually to $28{ }^{\circ} \mathrm{C}$, and 60 to $65 \%$ humidity was maintained using a room temperature control system by the end of the experiment (day 35). The basal corn-soybean meal diets were formulated to meet or slightly exceed the nutritional requirements of broilers during the starter (days 1-25) and grower (days 26-35) phases, according to NRC (1994) recommendations for broiler chickens (Table 1). The broilers were allowed ad libitum access to feed and fresh water. The six experimental treatments (i.e., liquid form) were given to broilers during the entire experimental period as follows: a corn-soybean meal-based diet (NC; no antimicrobial compounds added) with 8 ppm ALA; $150 \mathrm{ppm}$ vitamin $\mathrm{C}$ and 75 ppm vitamin E (E-75); E-75 plus 8 ppm ALA (E-75-ALA); $150 \mathrm{ppm}$ vitamin $\mathrm{C}$ and $50 \mathrm{ppm}$ vitamin $\mathrm{E}$ (E-50) plus 8 ppm ALA (E-50-ALA); and 150 ppm vitamin $\mathrm{C}$ and 25 ppm vitamin E (E-25) plus 8 ppm ALA (E-25ALA). Birds were monitored for mortality two times a day throughout the experiment.

Feed intake (FI) and body weight (BW) were recorded weekly per cage, and feed conversion ratio (FCR) was

Table 1 - Composition of the experimental diets

\begin{tabular}{|c|c|c|}
\hline \multirow{2}{*}{ Item } & \multicolumn{2}{|c|}{ Diet } \\
\hline & 1-3 weeks & 3-5 weeks \\
\hline \multicolumn{3}{|l|}{ Ingredient, $\%$} \\
\hline Corn & 29.64 & 32.26 \\
\hline Wheat & 30.00 & 30.00 \\
\hline Soybean meal & 28.67 & 26.71 \\
\hline Canola meal & 4.00 & 4.00 \\
\hline Vegetable oil & 4.05 & 4.30 \\
\hline Salt & 0.26 & 0.29 \\
\hline Limestone & 1.02 & 1.51 \\
\hline Choline & 0.12 & 0.10 \\
\hline Dicalcium phosphate & 1.04 & 0.88 \\
\hline Vitamin/Mineral premix ${ }^{1}$ & 0.26 & 0.26 \\
\hline L-lysine & 0.66 & 0.38 \\
\hline DL-methionine & 0.29 & 0.30 \\
\hline \multicolumn{3}{|l|}{ Calculated analysis } \\
\hline Crude protein, $\%$ & 20 & 19 \\
\hline Metabolizable energy, kcal & 3200 & 3200 \\
\hline Lysine, $\%$ & 1.17 & 1.07 \\
\hline Methionine, \% & 0.56 & 0.53 \\
\hline \multicolumn{3}{|c|}{$\begin{array}{l}{ }^{1} \text { Provided the following nutrients (per kg of air-dry diet): vit. A - } 12,000 \mathrm{IU} \text {; vi } \\
\mathrm{D}-33,000 \mathrm{IU} \text {; vit. E }-15 \mathrm{mg} \text {; vit. } \mathrm{K}-2 \mathrm{mg} \text {; thiamine - } 2 \mathrm{mg} \text {; riboflavin }-6 \mathrm{mg} \\
\text { pyridoxine }-2 \mathrm{mg} \text {; calcium pantothenate }-0.03 \mathrm{mg} \text {; folic acid }-0.2 \mathrm{mg} \text {; niacin }-45 \mathrm{mg} \\
\text { biotin }-0.15 \mu \mathrm{g} \text {; calcium }-0.5 \% \text {; Co }-0.5 \mathrm{mg} \text { (as cobalt sulfate); } \mathrm{Cu}-10 \mathrm{~m} \\
\text { (as copper sulfate); iodine - } 0.9 \mathrm{mg} \text { (as potassium iodine); iron - } 80 \mathrm{mg} \text { (as ferrou } \\
\text { sulfate); } \mathrm{Mn}-80 \mathrm{mg} \text { (as manganous oxide); Se - } 0.2 \mathrm{mg} \text { (as sodium selenite } \\
\mathrm{Zn}-80 \mathrm{mg} \text { (as zinc oxide). }\end{array}$} \\
\hline
\end{tabular}

R. Bras. Zootec., 45(3):113-120, 2016 
calculated as FI divided by body weight gain (BWG) every week, for a 5-week period. At day 21, one bird per pen was selected to obtain ileum tissue to measure villus height and crypt depth. The birds were euthanized via cervical dislocation after a $12 \mathrm{~h}$ fast. Fragments of approximately $5 \mathrm{~cm}$ in length were obtained from the ileum, between Meckel's diverticulum and the anterior portion of the ileocecal junction. The excised fragments were immersed in a phosphate-buffered formalin solution. Two portions per sample were cut perpendicular to the longitudinal axis of the intestine and embedded in paraffin wax. Transverse sections were cut $(3 \sim 5 \mu \mathrm{m})$. In the morphometric study, images were captured using a light microscope and a system that analyzes computerized images (Bio-Rad Microscience, UK). The height of 10 well oriented villi and their associated crypts were measured from each replicate per segment. The mean was obtained from these values. At the end of the experiment, one bird per pen was selected randomly. All birds fasted for $12 \mathrm{~h}$ were euthanized by exsanguination for carcass data. The carcasses were eviscerated manually and then immediately stored at $-20{ }^{\circ} \mathrm{C}$ for subsequent analysis.

After the carcasses were thawed at room temperature, each breast and leg meat sample was obtained from each carcass, and then meat quality associated with antioxidative activity was analyzed.

The $\mathrm{pH}$ values of leg meat and breast meat were assessed. Briefly, $10 \mathrm{~g}$ of sample were homogenized for $30 \mathrm{~s}$ using a stomacher (400 Lab blender, Seward, England) in $100 \mathrm{~mL}$ distilled water; afterwards, the $\mathrm{pH}$ of the sample was measured using a pH meter (WTW pH 720, Germany).

To determine the cooking loss, each sample was cut into $2.5 \mathrm{~cm}$ thick slices that were then packaged in polyethylene bags and placed in an $80^{\circ} \mathrm{C}$ water bath for $30 \mathrm{~min}$. The samples were then removed and cooled at room temperature for $30 \mathrm{~min}$, after which the cooking loss values were calculated based on the difference in the weight of the meat before and after cooking (Barbanti and Pasquini, 2005).

The thiobarbituric acid (TBA) values were measured according to the modified extraction method described by Witte et al. (1970). Briefly, $10 \mathrm{~g}$ of each sample, $15 \mathrm{~mL}$ of cold $10 \%$ perchloric acid, and $25 \mathrm{~mL}$ distilled water were added to this sample. After homogenizing the mixture at $10,000 \mathrm{rpm}$ for $10 \mathrm{~s}$ in a homogenizer (AM-Series, Kaisha Ltd., Japan), the homogenate was filtered using qualitative filter paper no. 2. After adding and completely mixing $5 \mathrm{~mL}$ of the filtrate solution and $5 \mathrm{~mL}$ of $0.02 \mathrm{M}$ TBA solution, the solution was allowed to stand for $16 \mathrm{~h}$ in a cool and dark place. The absorbance was measured at $529 \mathrm{~nm}$ suing a spectrophotometer (DU-650, Beckman,
USA). 1,1,3,3,-Tetra 1,1,3,3,-Tetraethoxypropane (SigmaAldrich, St. Louis, MO, USA) was used as standard for TBA assay. Thiobarbituric acid values were expressed as milligrams of malonaldehyde (MA) per kilogram of sample (mg MA $/ \mathrm{kg}$ ), and the standard curve equation used was $\mathrm{y}=0.1975 \mathrm{x}+0.0011(\mathrm{r}=0.999)$, in which $\mathrm{y}=$ absorbance for a given $\mathrm{x}$, the TBA value.

The 1,1-diphenyl-2-picrylhydrazyl radical scavenging activity of leg and breast meats was determined according to the modified method described by Blois (1958). Briefly, $1 \mathrm{~mL}$ of lemon balm ethanol extract and $1 \mathrm{~mL}$ of $0.2 \mathrm{mM}$ DPPH were added to a test tube and mixed for $30 \mathrm{~min}$ at $37^{\circ} \mathrm{C}$, and the absorbance of the mixture was measured at 517 nm using a UV-spectrophotometer (Shimadzu UV-1601PC, Japan). At the same time, antioxidant activity was measured by the same method using ascorbic acid (Sigma-Aldrich, St. Louis, MO, USA), which is a natural antioxidant, as well as butylated hydroxyanisole (BHA) and butylated hydroxytoluene (BHT), which are synthetic antioxidants, as a positive control group. The DPPH radical scavenging activity of each sample was calculated using the following formula: (absorbance of sample addition group/absorbance of the control group) $\times 100$. Ascorbic acid, BHA, and BHT were used at $0.5 \mathrm{mg} / \mathrm{mL}$. Sample concentration providing $50 \%$ inhibition (IC50) was calculated from the graph of inhibition percentage against sample concentration.

Data were analyzed univariately in a normal-linear model using the GLM procedure of SPSS (version 21.0, SPSS Inc., Chicago, Illinois, USA). The pen was the experimental unit for the growth performance (i.e., average daily gain $[A D G]$, average daily feed intake [ADFI], and feed conversion ratio $[\mathrm{FCR}])$. Initial $\mathrm{BW}$ was included in the model as a covariate for analyses of growth performance data. The individual chicken was considered the experimental unit for intestinal morphology and meat quality traits. Statistical significance was accepted at $\mathrm{P}<0.05$. Pair-wise comparisons between means were made when appropriate using Fisher's protected LSD analysis when a significant treatment effect was observed.

\section{Results}

The results indicated the effects of antioxidant supplementation on broiler performance under moderate heat stress (Table 2). No significant difference appeared $(\mathrm{P}>0.05)$ in ADFI, FCR, or mortality among dietary treatments. However, birds fed E-75-ALA had higher $(\mathrm{P}<0.05)$ ADG than birds fed NC for 35 days (Table 2).

Birds fed E-75-ALA and E-50-ALA had improved $(\mathrm{P}<0.05)$ villus height on day 21 . Nonetheless, birds fed 
E-75-ALA had lower $(\mathrm{P}<0.05)$ crypt depth compared with negative control. Furthermore, birds fed E-75-ALA had higher $(\mathrm{P}<0.05)$ villus height:crypt depth ratio compared with NC, PC, and E-75 (Table 3).

No difference was found $(\mathrm{P}>0.05)$ in the $\mathrm{pH}$ values of leg or breast meat among the dietary treatments (Table 4). Birds fed E-75-ALA had higher $(\mathrm{P}<0.05)$ breast and leg meat cooking loss compared with NC (Table 4). Birds fed ALA combination had higher $(\mathrm{P}<0.05) \mathrm{DPPH}$ radical scavenging activity of leg and breast meat among the dietary treatments. Similarly, birds fed E-75-ALA had lower $(\mathrm{P}<0.05)$ thiobarbituric acid reactive substances (TBARS) value in leg and breast meat compared with the negative control.

Table 2 - Effect of dietary antioxidant on growth performance and mortality rate of broiler chickens from 1 to 35 days of age

\begin{tabular}{|c|c|c|c|c|c|c|c|c|}
\hline Item & $\mathrm{NC}$ & $\mathrm{PC}$ & E-75 & E-75-ALA & E-50-ALA & E-25-ALA & SEM $^{1}$ & P-value \\
\hline \multicolumn{9}{|l|}{ BW, g/bird } \\
\hline Days 1-7 & 182.2 & 185.7 & 188.0 & 187.7 & 185.4 & 185.6 & 0.84 & 0.619 \\
\hline Days 8-14 & 481.4 & 482.9 & 486.2 & 498.7 & 494.4 & 490.9 & 3.94 & 0.369 \\
\hline Days $22-28$ & 1485.6 & 1528.7 & 1553.2 & 1595.6 & 1564.3 & 1553.4 & 10.52 & 0.083 \\
\hline Days 29-35 & $1912.7 \mathrm{a}$ & $1964.6 \mathrm{ab}$ & $1998.8 \mathrm{ab}$ & $2038.2 b$ & 1994.6ab & $1983.5 \mathrm{ab}$ & 10.36 & 0.009 \\
\hline Days 1-35 & $992.1 \mathrm{a}$ & $1014.9 \mathrm{ab}$ & $1031.0 \mathrm{ab}$ & $1050.0 \mathrm{~b}$ & $1031.9 \mathrm{ab}$ & $1025.9 \mathrm{ab}$ & 3.95 & 0.007 \\
\hline Days 1-7 & 20.3 & 20.8 & 21.1 & 21.1 & 20.8 & 20.8 & 0.11 & 0.291 \\
\hline Days 8-14 & 42.7 & 42.5 & 42.6 & 44.4 & 44.1 & 43.6 & 0.57 & 0.892 \\
\hline Days $15-21$ & 59.6 & 61.4 & 63.2 & 61.5 & 60.9 & 60.8 & 1.34 & 0.989 \\
\hline Days 22-28 & 83.8 & 88.0 & 89.2 & 95.2 & 91.9 & 91.0 & 1.44 & 0.325 \\
\hline Days 29-35 & 61.0 & 62.3 & 63.7 & 63.2 & 61.5 & 61.4 & 2.11 & 0.999 \\
\hline Days 1-35 & $53.5 \mathrm{a}$ & $55.0 \mathrm{ab}$ & $56.0 \mathrm{~b}$ & $57.1 \mathrm{~b}$ & $55.8 \mathrm{ab}$ & $55.5 \mathrm{ab}$ & 0.34 & 0.051 \\
\hline Days 22-28 & $131.8 \mathrm{ab}$ & $127.9 \mathrm{ab}$ & $140.6 \mathrm{~b}$ & $128.4 \mathrm{ab}$ & $120.4 \mathrm{a}$ & $126.8 \mathrm{ab}$ & 2.06 & 0.106 \\
\hline Days 29-35 & 110.8 & 111.6 & 110.7 & 117.5 & 109.1 & 110.9 & 2.58 & 0.975 \\
\hline Days 1-35 & 82.8 & 80.5 & 84.1 & 83.3 & 79.3 & 81.9 & 0.80 & 0.683 \\
\hline \multicolumn{9}{|c|}{ Feed conversion, $\mathrm{g} / \mathrm{g}$} \\
\hline Days 1-7 & 1.10 & 1.07 & 1.12 & 1.13 & 1.17 & 1.16 & 0.01 & 0.255 \\
\hline Days 8-14 & 1.59 & 1.50 & 1.58 & 1.51 & 1.61 & 1.56 & 0.03 & 0.925 \\
\hline Days $15-21$ & 1.39 & 1.26 & 1.26 & 1.31 & 1.20 & 1.37 & 0.04 & 0.705 \\
\hline Days $22-28$ & $1.59 \mathrm{~b}$ & $1.46 \mathrm{ab}$ & $1.59 \mathrm{~b}$ & $1.35 \mathrm{a}$ & $1.32 \mathrm{a}$ & $1.40 \mathrm{ab}$ & 0.03 & 0.039 \\
\hline Days 29-35 & 1.93 & 1.97 & 1.74 & 1.95 & 1.92 & 1.88 & 0.10 & 0.993 \\
\hline Days 1-35 & 1.52 & 1.45 & 1.46 & 1.45 & 1.44 & 1.48 & 0.02 & 0.952 \\
\hline \multicolumn{9}{|c|}{ Mortality, $n$ of birds } \\
\hline Days 1-7 & 0.0 & 0.0 & 0.0 & 0.0 & 0.0 & 0.0 & 0.02 & 1.000 \\
\hline
\end{tabular}

BW - body weight; ADG - average daily gain; ADFI - average daily feed intake.

$\mathrm{NC}$ - negative control; PC - positive control (8 ppm alpha-lipoic acid); E-75 - 150 ppm vitamin C and 75 ppm vitamin E; E-75-ALA - E-75 plus ALA; E-50-ALA - 150 ppm vitamin C and $50 \mathrm{ppm}$ vitamin E (E-50) plus ALA; E-25-ALA - $150 \mathrm{ppm}$ vitamin C and $25 \mathrm{ppm}$ vitamin E (E-25) plus ALA (E-25-ALA).

${ }^{1}$ Pooled standard error of the mean.

$\mathrm{ab}$ - means in the same row with different letters differ $(\mathrm{P}<0.05)$.

Table 3 - Effect of dietary antioxidant on villus height and crypt depth of broiler chickens on day 21

\begin{tabular}{|c|c|c|c|c|c|c|c|c|}
\hline Item & $\mathrm{NC}$ & $\mathrm{PC}$ & E-75 & E-75-ALA & E-50-ALA & E-25-ALA & SEM $^{1}$ & P-value \\
\hline Villus height, $\mu \mathrm{m}$ & $439.9 \mathrm{a}$ & $463.6 \mathrm{ab}$ & $475.0 \mathrm{ab}$ & $517.1 \mathrm{~b}$ & $517.6 \mathrm{~b}$ & $478.8 \mathrm{ab}$ & 5.17 & 0.002 \\
\hline Crypt depth, $\mu \mathrm{m}$ & $140.2 \mathrm{a}$ & $128.9 \mathrm{ab}$ & $118.2 \mathrm{abc}$ & $99.8 \mathrm{c}$ & $110.2 \mathrm{bc}$ & $113.0 \mathrm{bc}$ & 2.10 & 0.001 \\
\hline Villus height:Crypt depth ratio & $3.17 \mathrm{~d}$ & $3.63 \mathrm{~cd}$ & $4.03 \mathrm{bcd}$ & $5.28 \mathrm{a}$ & $4.78 \mathrm{ab}$ & $4.30 \mathrm{abc}$ & 0.087 & 0.001 \\
\hline
\end{tabular}

NC - negative control; PC - positive control (8 ppm alpha-lipoic acid); E-75 - 150 ppm vitamin C and 75 ppm vitamin E; E-75-ALA - E-75 plus ALA; E-50-ALA - 150 ppm vitamin C and $50 \mathrm{ppm}$ vitamin E (E-50) plus ALA; E-25-ALA - 150 ppm vitamin C and $25 \mathrm{ppm}$ vitamin E (E-25) plus ALA (E-25-ALA).

${ }^{1}$ Pooled standard error of the mean.

$\mathrm{abc}-$ means in the same row with different letters differ $(\mathrm{P}<0.05)$ 
Table 4 - Effect of dietary antioxidant on meat quality traits of broiler chickens on day 35

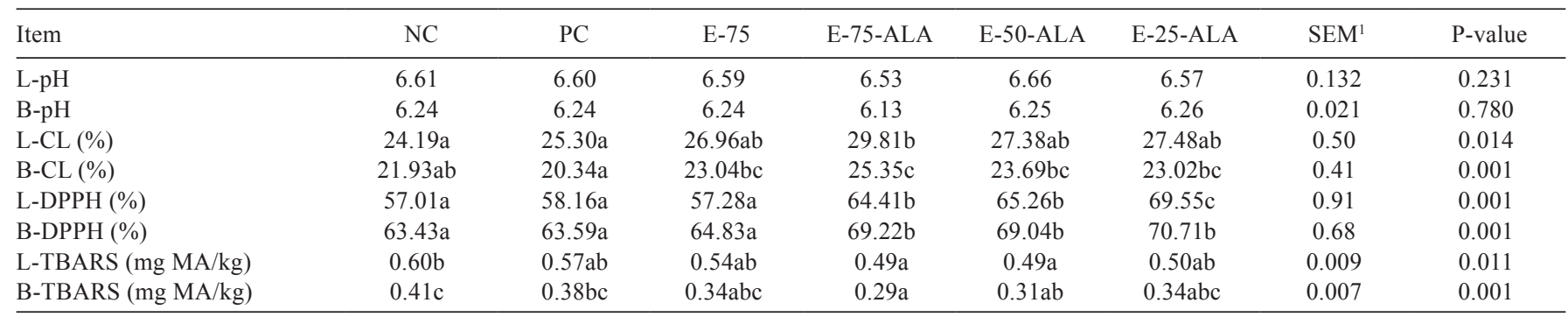

L - leg meat; B - breast meat; CL - cooking loss; DPPH - DPPH free radical scavenging activity; MA - malonaldehyde.

$\mathrm{NC}$ - negative control; PC - positive control (8 ppm alpha-lipoic acid); E-75 - 150 ppm vitamin C and 75 ppm vitamin E; E-75-ALA - E-75 plus ALA; E-50-ALA - 150 ppm vitamin C and $50 \mathrm{ppm}$ vitamin E (E-50) plus ALA; E-25-ALA - $150 \mathrm{ppm}$ vitamin C and $25 \mathrm{ppm}$ vitamin E (E-25) plus ALA (E-25-ALA).

${ }^{1}$ Pooled standard error of the mean.

$\mathrm{abc}-$ means in the same row with different letters differ $(\mathrm{P}<0.05)$.

\section{Discussion}

In chicken rearing, heat stress has caused economic loss and concurrent welfare issues. The best way to avoid heat stress is maintaining the right ambient temperature, but it is costly to install a cooling system and keep that ambient temperature in cages, particularly in hot areas or in the summer season. Thus, many studies have focused on manipulating the diet to reduce the physiological and physical damages of broilers from heat stress. In the present study, antioxidants (vit. E, vit. C, and ALA) were added to drinking water, and the combination of antioxidants positively affected growth performance, intestinal morphology, and meat quality under moderate heat stress, suggesting that supplementation of dietary antioxidants could ameliorate the raising and productivity of broiler chickens. Sigel et al. (1995) reported that growth performance was decreased in birds when the ambient temperature rise was beyond the thermoneutral zone (i.e., over $32{ }^{\circ} \mathrm{C}$ ). In the present study, the birds fed a diet without any antioxidants showed decreased final $\mathrm{BW}$ and $\mathrm{ADG}$ compared with those fed a diet supplemented with vit. C, vit. E (75 ppm), and ALA (Table 2). This result was in agreement with previous reports that indicated decreased BW from heat stress, but that were compensated for by the addition of antioxidants such as ascorbic acid (Imik et al., 2012; Sahin et al., 2003). Our results suggested that antioxidants may enhance digestibility, resulting in increasing ADG and BW, although no significant difference was observed in ADFI (Table 2). Indeed, Wallis and Balnave (1984) reported that high environmental temperatures had detrimental effects on broilers by decreasing their digestibility of amino acids. Larbier et al. (1993) found that high temperature condition decreased the true digestibility of protein, which might deter the activity of protein digestive enzymes (trypsin, chymotrypsin, and amylase) under heat stress. These negative influences on digestibility were moderated through the supplementation of the antioxidant vitamins. Sahin and Kucuk (2001) demonstrated that the combination of $200 \mathrm{mg}$ vit. $\mathrm{C}$ and $250 \mathrm{mg}$ vit. E improved nutrient digestibility of dry matter, organic matter, crude protein, and ether extract in Japanese quails, which was also confirmed in broilers exposed to heat stress (Sahin et al., 2003). Nevertheless, we were not in the position to determine digestibility in the present study.

The present study could anticipate that supplementation of antioxidants increased the digestive capacity under heat stress, although there was no effect of antioxidants on feed intake (Tables 2 and 3). It is known that the gastrointestinal tract is sensitive to stressors (Suzuki, 1983; Burkholder et al., 2008). When broilers were exposed to feed withdrawal and heat stress, ileal morphology became aberrant, leading to increased attachment of Salmonella Enteritidis (Burkholder et al., 2008). Also, diminished feed intake due to heat stress affected the height of villi in broilers (Tarachai and Yamauchi, 2000). It is well known that the villus height: crypt depth ratio is the gut health index (Pluske, 1997). When the villus height:crypt depth ratio was low, the intestinal environment became more favorable to nutrition absorption than vice versa (Pluske, 1997). Caspary (1992) reported that increasing the villus height is considered a means to broaden the surface area, thereby improving the absorption of available nutrients. Thus, shortening villi can take a toll on the nutrient absorption by reducing the surface area. Proliferation of stem cells is present at the base of the crypt, which differentiates mostly from enterocytes. The enterocytes migrate up the villus and are extruded from the villus tip into the lumen (Imondi and Bird, 1966). In the course of the process, the enterocytes become mature and functional in terms of nutrient absorption and mucin secretion (Wright and Alison, 1984). In this regard, poor nutrient absorption may occur due to the decrease in villus height and increase in crypt depth. Similarly, Fan et al. (1997) reported that the villus height:crypt depth 
ratio was closely associated with increased epithelial cell turnover. Also, Samanya and Yamauchi (2002) observed that longer villi were correlated with activated cell mitosis in chickens.

The morphometric analysis results in the present study showed that the supplementation of antioxidants increased villus height but decreased crypt depth in broilers reared under chronic heat stress. The birds supplemented with $150 \mathrm{ppm}$ vit. C, $75 \mathrm{ppm}$ or $50 \mathrm{ppm}$ vit. E, and 8 ppm ALA had significantly higher villus height than negative control, whereas no significant difference occurred between positive and negative control groups (Table 3). Similar results were obtained for crypt depth and villus height: crypt depth ratio, except that supplementation of $150 \mathrm{ppm}$ vit. C, $50 \mathrm{ppm}$ vit. E, and $8 \mathrm{ppm}$ ALA also provided a significantly higher villus height (Table 3 ). Based on these results, it seems that supplementation of 8 ppm ALA cannot ameliorate impaired intestinal morphology per se. In a sense, antioxidant activities of ALA can be expressed when it is supplemented together with vit. E and vit. C. According to Packer et al. (1995), it appears that ALA lacks biochemical capacity for scavenging the superoxide radical, hydrogen peroxide, and the peroxyl radical. Although ALA was ineffective against some oxidants, it has been widely known that ALA effectively interacts with other antioxidants by increasing the antioxidant activity of one another. For example, ALA and vit. C continuously recycled vit. E, which was predominantly used to protect membranes from lipid peroxidation as the major chain breaking antioxidant (Sies et al., 1994; Packer, 1992). Alpha-lipoic acid is also capable of recycling vit. $\mathrm{E}$ by regenerating vit. $\mathrm{C}$ (Biewenga et al., 1997). In addition, microsomal lipid peroxidation was inhibited by the reduced form of ALA, which is a dihydrolipoic acid in the presence of vit. E (Scholich et al., 1989). Alpha-lipoic acid inclusion in vivo increases the level of ubiquinol, which is the substance known to recycle vit. E under oxidative stress circumstances (Götz et al., 1994; Kagan et al., 1990). A study showed that $500 \mathrm{mg}$ vit. E/ $\mathrm{kg}$ did not have any effects on villus height, crypt depth, and villus height:crypt depth ratio (Murakami et al., 2007). Thus, vit. E may not act solely on the intestinal mucosa effectively. Turan and Mahmood (2007) suggested that the liberation of enterocytes from the villus tip cells due to apoptosis generated the large amount of free radicals in villus tip cells (Turan and Mahmood, 2007). In the present study, combination of antioxidants (vit. E, vit. C, and ALA) may effectively scavenge the generated free radicals caused by heat stress, consequently resulting in improved ileal morphology.

The detrimental influences in broilers by heat stress were found not only in their growth performance, but also meat quality. Heat stress induced alterations of muscle metabolism and membrane integrity, which could be associated with the meat quality (Lu et al., 2007; Zhang et al., 2012; Sanderock et al., 2001). The $\mathrm{pH}$ value of the meat is known to be an important physical factor in the postmortem stage. Because it indicates meat color, cooking loss, and meat sensory quality (Ahn and Maurer, 1990; Guignot et al., 1994). In this study, the $\mathrm{pH}$ value of both leg and breast meat was numerically lower in dietary vit. C, vit. E (75 ppm), and ALA than negative control (Table 4). We assume that antioxidants might have a positive effect on the $\mathrm{pH}$ value in breast and drumstick meat during storage. The 1,1-diphenyl-2-picrylhydrazyl free radical scavenging activity is a simple method to evaluate antioxidative activity (Yamaguchi, 1998; Arshad et al., 2011). In the present study, the diets including ALA showed significantly higher DPPH free radical scavenging activity than negative control (Table 4). These results suggest that breast and leg meat from the broilers that drank liquid antioxidants might have electron donors to neutralize free radicals, which is in agreement with results of a previous study (Jung et al., 2010). Many studies reported that chickens reared at a high temperatures had increased TBARS in plasma, organs, and carcass (Lin et al., 2000; Mahmoud and Edens, 2003; Gao et al., 2010). The supplementation of antioxidants prevented lipid oxidation in chicken meat that decreased TBARS value, which is a consequence of oxidant stress (Jung et al., 2010; Cortinas et al., 2005). The findings in the present study showed that both leg and breast meat samples from the broilers that drank the water supplemented with vit. C, vit. E (75 ppm), and ALA had lower TBARS values than the negative control group, suggesting that vit. E might improve lipid stability and reduce lipid oxidation in chicken meat (Cortinas et al., 2005). Gao et al. (2010) demonstrated that the high level of vit. E was effective for the performance of broilers by reducing oxidative stress.

\section{Conclusions}

Broilers that drink water supplemented with $150 \mathrm{ppm}$ vitamin $\mathrm{C}, 75 \mathrm{ppm}$ vitamin $\mathrm{E}$, and $8 \mathrm{ppm}$ alpha-lipoic acid reared under high ambient temperature have positive results in growth performance, ileal morphometry, and meat quality. Also, the optimal vitamin E level of $75 \mathrm{ppm}$ when in combination with vitamin $\mathrm{C}$ at $150 \mathrm{ppm}$ and alpha-lipoic acid at $8 \mathrm{ppm}$ plays important roles in antioxidant activity, ameliorating heat stress. Birds under heat stress consume more water than food. Consequently, broiler chickens are expected to become less susceptible to heat stress by drinking water supplemented with antioxidants. 


\section{Acknowledgments}

Financial support from Biogenoci Co. Ltd. is greatly appreciated. This paper was financially supported by the research fund of Chungnam National University. The authors thank Mr. Samiru Sudharaka Wickramasuriya and Mr. Cheol Woo Lee for the technical assistance.

\section{References}

Ahn, D. U. and Maurer, A. J. 1990. Poultry meat color: kinds of heme pigments and concentrations of the ligands. Poultry Science 69:157-165.

Arshad, M. S.; Anjum, F. M.; Asghar, A.; Khan, M. I.; Yasin, M.; Shahid, M. and El-Ghorab, A. H. 2011. Lipid stability and antioxidant profile of microsomal fraction of broiler meat enriched with $\alpha$-lipoic acid and $\alpha$-tocopherol acetate. Journal of Agricultural Food Chemistry 59:7346-7352.

Bai, X. M.; Ma, Q. G.; Zhao, L. H.; Xi, L. and Ji, C. 2012. Effects of alpha-lipoic acid supplementation on antioxidative ability and performance of sows and nursing piglets. Journal of Animal Physiology and Animal Nutrition 96:955-961.

Barbanti, D. and Pasquini, M. 2005. Influence of cooking conditions on cooking loss and tenderness of raw and marinated chicken breast meat. LWT-Food Science and Technology 38:895-901.

Biewenga, G. P.; Haenen, G. R. and Bast, A. 1997. The pharmacology of the antioxidant lipoic acid. General Pharmacology: The Vascular System 29:315-331.

Blois, M. S. 1958. Antioxidant determination by the use of a stable free radical. Nature 181:1199-1200.

Burkholder, K. M.; Thompson, K. L.; Einstein, M. E.; Applegate, T. J. and Patterson, J. A. 2008. Influence of stressors on normal intestinal microbiota, intestinal morphology, and susceptibility to Salmonella enteritidis colonization in broilers. Poultry Science 87:1734-1741.

Caspary, W. F. 1992. Physiology and pathophysiology of intestinal absorption. The American Journal of Clinical Nutrition 55:299S-308S.

Cortinas, L.; Barroeta, A.; Villaverde, C.; Galobart, J.; Guardiola, F. and Baucells, M. D. 2005. Influence of the dietary polyunsaturation level on chicken meat quality: Lipid oxidation. Poultry Science $84: 48-55$

Charles, D. R. 2002. Responses to the thermal environment. p.1-16. In: Poultry environment problems: a guide to solutions. Charles, D. R. and Walker, A. W., eds. Nottingham University Press, UK.

Dröge, W. 2002. Free radicals in the physiological control of cell function. Physiological. Reviews 82:47-95.

El-Senousey, H. K.; Fouad, A. M.; Yao, J. H.; Zhang, Z. G. and Shen, Q. W. 2013. Dietary alpha lipoic acid improves body composition, meat quality and decreases collagen content in muscle of broiler chickens. Asian-Australasian Journal of Animal Science 26:394-400.

Fan, Y. K.; Croom, J.; Christensen, V. L.; Black, B. L.; Bird, A. R.; Daniel, L. R.; McBride, B. W. and Eisen, E. J. 1997. Jejunal glucose uptake and oxygen consumption in turkey poults selected for rapid growth. Poultry Science 76:1738-1745.

Gao, J.; Lin, H.; Wang, X. J.; Song, Z. G. and Jiao, H. C. 2010. Vitamin E supplementation alleviates the oxidative stress induced by dexamethasone treatment and improves meat quality in broiler chickens. Poultry Science 89:318-327.
Götz, M. E.; Künig, G.; Riederer, P. and Youdim, M. B. 1994. Oxidative stress: free radical production in neural degeneration. Pharmacology \& Therapeutics 63:37-122.

Guignot, F.; Touraille, C.; Ouali, A.; Renerre, M. and Monin, G. 1994. Relationships between post-mortem $\mathrm{pH}$ changes and some traits of sensory quality in veal. Meat Science 37:315-325.

Halıcı, M.; Imik, H.; Koç, M. and Gümüş, R. 2012. Effects of $\alpha$-lipoic acid, vitamins $\mathrm{E}$ and $\mathrm{C}$ upon the heat stress in Japanese quails. Journal of Animal Physiology and Animal Nutrition 96:408-415.

Imik, H.; Atasever, M. A.; Urcar, S.; Ozlu, H.; Gumus, R. and Atasever, M. 2012. Meat quality of heat stress exposed broilers and effect of protein and vitamin E. British Poultry Science 53:689-698.

Imondi, A. R. and Bird, F. H. 1966. The turnover of intestinal epithelium in the chick. Poultry Science 45:142-147.

Jung, S.; Choe, J. H.; Kim, B.; Yun, H.; Kruk, Z. A. and Jo, C. 2010. Effect of dietary mixture of gallic acid and linoleic acid on antioxidative potential and quality of breast meat from broilers. Meat Science 86:520-526.

Kagan, V. E.; Serbinova, E. and Packer, L. 1990. Antioxidant effects of ubiquinones in microsomes and mitochondria are mediated by tocopherol recycling. Biochemical and Biophysical Research Communications 169:851-857.

Kagan, V. E.; Shvedova, A.; Serbinova, E.; Khan, S.; Swanson, C.; Powell, R. and Packer, L. 1992. Dihydrolipoic acid: A universal antioxidant both in the membrane and in the aqueous phase - reduction of peroxyl, ascorbyl and chromanoxyl radicals. Biochemical Pharmacology 44:1637-1649.

Lara, L. J. and Rostagno, M. H. 2013. Impact of heat stress on poultry production. Animals 3:356-369.

Larbier, M.; Chagneau, A. M. and Geraert, P. A. 1993. Influence of ambient temperature on true digestibility of protein and amino acids of rapeseed and soybean meals in broilers. Poultry Science 72:289-295.

Lin, H.; Du, R. and Zhang, Z. Y. 2000. Peroxide status in tissues of heat-stressed broilers. Asian-Australasian Journal of Animal Science 13:1373-1376.

Lu, Q.; Wen, J. and Zhang, H. 2007. Effect of chronic heat exposure on fat deposition and meat quality in two genetic types of chicken. Poultry Science 86:1059-1064.

Mahmoud, K. Z. and Edens, F. W. 2003. Influence of selenium sources on age-related and mild heat stress-related changes of blood and liver glutathione redox cycle in broiler chickens (Gallus domesticus). Comparative Biochemistry and Physiology - Part B: Biochemistry \& Molecular Biology 136:921-934.

Murakami, A. E.; Sakamoto, M. I.; Natali, M. R. M.; Souza, L. M. G. and Franco, J. R. G. 2007. Supplementation of glutamine and vitamin E on the morphometry of the intestinal mucosa in broiler chickens. Poultry Science 86:488-495.

NRC - National Research Council. 1994. Nutrient requirements of poultry. National Academy Press, Washington, DC.

Packer, L. 1992. New horizons in antioxidant research: Action of the thioctic acid/dihydrolipoic acid couple in biological systems. p.35-44. In: Thioctsaure. 2nd International Thictic Acid Workshop. Universimed Verlag GmbH, Frankfurt.

Packer, L.; Tritschler, H. J. and Wessel, K. 1996. Neuroprotection by the metabolic antioxidant $\alpha$-lipoic acid. Free Radical Biology \& Medicine 22:359-378.

Packer, L.; Witt, E. H. and Tritschler, H. J. 1995. Alpha-lipoic acid as a biological antioxidant. Free Radical Biology \& Medicine 19:227-250.

Pluske, J. R.; Hampson D. J. and Williams, I. H. 1997. Factors influencing the structure and function of the small intestine in the weaned pig: a review. Livestock Production Science 51:215-236. 
Quinteiro-Filho, W. M.; Rodrigues, M. V.; Ribeiro, A.; Ferraz-dePaula, V.; Pinheiro, M. L.; Sa, L. R. M.; Ferreira, A. J. P. and Palermo-Neto, J. 2012. Acute heat stress impairs performance parameters and induces mild intestinal enteritis in broiler chickens: Role of acute hypothalamic-pituitary-adrenal axis activation. Journal of Animal Science 90:1986-1994.

Reed, L. J. 1957. The chemistry and function of lipoic acid. Advances in Enzymology 18:319-347.

Sahin, K. and Kucuk, O. 2001. Effects of vitamin C and vitamin E on performance, digestion of nutrients and carcass characteristics of Japanese quails reared under chronic heat stress (34 C). Journal of Animal Physiology and Animal Nutrition 85:335-341.

Sahin, K.; Sahin, N. and Kucuk, O. 2003. Effects of chromium, and ascorbic acid supplementation on growth, carcass traits, serum metabolites, and antioxidant status of broiler chickens reared at a high ambient temperature (32 C). Nutrition Research 23:225-238.

Samaya, M. and Yamauchi, K. E. 2002. Histological alterations of intestinal villi in chickens fed dried Bacillus subtilis var. natto. Comparative Biochemestry and Physiology Part: A Molecular \& Integrative Physiology 133:95-104.

Sandercock, D. A.; Hunter, R. R.; Nute, G. R.; Mitchell, M. A. and Hocking, P. M. 2001. Acute heat stress-induced alterations in blood acid-base status and skeletal muscle membrane integrity in broiler chickens at two ages: Implications for meat quality. Poultry Science 80:418-425.

Scholich, H.; Murphy, M. E. and Sies, H. 1989. Antioxidant activity of dihydrolipoate against microsomal lipid peroxidation and its dependence on $\alpha$-tocopherol. Biochimica et Biophysica Acta (BBA) - Lipids and Lipid Metabolism 1001:256-261.

Scott, B. C.; Aruoma, O. I.; Evans, P. J.; O’Neill, C.; Van der Vliet, A.; Cross, C. E.; Tritschler, H. and Halliwell, B. 1994. Lipoic and dihydrolipoic acids as antioxidants. A critical evaluation. Free Radical Research 20:119-133.

Sies, H. 1994. Strategies of antioxidant defense. p.101-107. In: EJB Reviews 1993. Springer Berlin Heidelberg.

Sigel, H. S. 1995. Gordon memorial lecture. Stress, strains and resistance. British Poultry Science 36:3-22.

Sohail, M. U.; Hume, M. E.; Byrd, J. A.; Nisbet, D. J.; Ijaz, A.; Sohail, A.; Shabbir M. Z. and Rehman H. 2012. Effect of supplementation of prebiotic mannan-oligosaccharides and probiotic mixture on growth performance of broilers subjected to chronic heat stress. Poultry Science 91:2235-2240.

Stevens, B.; Perez, S. R. and Small, R. D. 1974. The photoperoxidation of unsaturated organic molecules: IX. Lipoic acid inhibition of rubrene autoperoxidation. Photochemistry and Photobiology 19:315-316.

Suzuki, K. 1983. The hand and environment (5):--Physiological changes of digital functions in two age groups studied by three stress tests under three environmental conditions. Nihon Seikeigeka Gakkai Zasshi 57:79-89.

Suzuki, Y. J.; Tsuchiya, M. and Packer L. 1991. Thioctic acid and dihydrolipoic acid are novel antioxidants which interact with reactive oxygen species. Free Radical Research 15:255-263.

Tarachai, P. and Yamauchi, K. 2000. Effects of luminal nutrient absorption, intraluminal physical stimulation, and intravenous parenteral alimentation on the recovery responses of duodenal villus morphology following feed withdrawal in chickens. Poultry Science 79:1578-1585.

Turan, A. and Mahmood, A. 2007. The profile of antioxidant systems and lipid peroxidation across the crypt-villus axis in rat intestine. Digestive Diseases and Science 52:1840-1844.

Wallis, I. R. and Balnave, D. 1984. The influence of environmental temperature, age and sex on the digestibility of amino acids in growing broiler chickens. British Poultry Science 25:401-407.

Witte, V. C.; Krause, G. F. and Bailey, M. E. 1970. A new extraction method for determining 2- thiobarbituric acid values of pork and beef during storage. Journal of Food Science 35:582-585.

Wright, N. A. and Alison, M. 1984. The biology of epithelial cell populations. Oxford University Press, New York.

Yamaguchi, T.; Takamura, H.; Matoba, T. and Terao, J. 1998. HPLC method for evaluation of the free radical-scavenging activity of foods by using 1, 1-diphenyl-2-picrylhydrazyl. Bioscience, Biotechnology, and Biochemistry 62:1201-1204.

Zhang, Z. Y.; Jia, G. Q.; Zuo, J. J.; Zhang, Y.; Lei, J.; Ren, L. and Feng, D. Y. 2012. Effects of constant and cyclic heat stress on muscle metabolism and meat quality of broiler breast fillet and thigh meat. Poultry Science 91:2931-2937. 